University of Windsor

Scholarship at UWindsor

\title{
Speech Acts and Indirect Threats in Ad Baculum Arguments: A Reply to Budzynska and Witek
}

Douglas Walton

University of Windsor, Centre for Research in Reasoning, Argumentation and Rhetoric

Follow this and additional works at: https://scholar.uwindsor.ca/crrarpub

Part of the Arts and Humanities Commons

\section{Recommended Citation}

Walton, Douglas. (2014). Speech Acts and Indirect Threats in Ad Baculum Arguments: A Reply to Budzynska and Witek. Argumentation, 28 (3), 317-324.

https://scholar.uwindsor.ca/crrarpub/14

This Article is brought to you for free and open access by the Centre for Research in Reasoning, Argumentation and Rhetoric (CRRAR) at Scholarship at UWindsor. It has been accepted for inclusion in CRRAR Publications by an authorized administrator of Scholarship at UWindsor. For more information, please contact scholarship@uwindsor.ca. 


\section{Speech Acts and Indirect Threats in Ad Baculum Arguments: A Reply to} Budzynska and Witek

Argumentation 28(3), 2014, 317-324

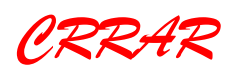

Abstract

The importance of speech acts for analyzing and evaluating argumentation in cases where it is suspected that the ad baculum fallacy has been committed is demonstrated in this paper by using a typical textbook example of this fallacy. It is shown how the argument in the example can be analyzed and evaluated using the devices of Gricean implicature and indirect speech acts. It is shown how these two devices can be applied to extrapolate the evidence furnished by the text and dialectical context of the example.

Key Words: fallacies, argument from negative consequences, strategic maneuvering, implicature.

The work of Budzynska and Witek (2014) is an important contribution to the ongoing research on the nature of the ad baculum argument and the ad hominem argument. In this paper I will focus on their analysis of the ad baculum argument, using an example to show how speech acts are essential to the modeling of this type of argument. Using their approach to address some interesting features of this example, I will argue that there is yet another factor that should be considered in modeling ad baculum arguments, namely contextual information about the framework of dialogue in which this type of argument is embedded.

Budzynska and Witek (2014) have shown that the tactics associated with ad hominem and ad baculum arguments are not purely inferential in nature, and that it is necessary to bring speech acts to bear on these forms of arguments to fully explain their dynamics. I will use an example to provide additional evidence to support their thesis in the case of the ad baculum argument. I will concur, based on this evidence, that it is vital to emphasize the importance of speech acts in order to analyze both reasonable and fallacious arguments based on threats. I will bring out the special importance of implicit speech acts as mediating factors in argumentation dialogues. Reed (2011) has shown that in order to tackle the challenge of modeling the argumentation structure of implicit speech acts, we need not only to use argument maps that represent a sequence of inferences chained together as arguments, but also dialogue structures that model how one type of utterance can follow from another as a reasonable response in a context of dialogue where there is an orderly communicative exchange between two or more parties. I will also argue that Gricean implicatures and conversational maxims are required to make sense of ad baculum arguments of the kind based on the making of a threat by one party to another.

\section{An Example of an Ad Baculum Argument}

Some of the most interesting and challenging examples of ad baculum arguments treated by the logic textbooks and other writings on the ad baculum fallacy concern the following type of example. This particular example is taken from (Walton, 2000, 123) where it was used to illustrate a typical type of example featured by the logic textbooks. 
A known gangster says to the owner of a small business: "You should pay us protection money, because this is a very dangerous neighborhood. The last guy who didn't pay had his store looted and destroyed, right after he failed to pay".

It is precisely this type of example that is so often used by the logic textbooks to illustrate the $\mathrm{ad}$ baculum fallacy. It is easy for students using the textbook to see that somehow the argument has gone wrong or is a bad one, but precise diagnosis of the failure is not an easy task. The problem is that such a threat made by a gangster is so obviously unfair and unpleasant that it is easy to jump to the conclusion that it represents some sort of illegitimate or unfair argument.

Let us begin by trying to configure the text of discourse in the example as an argument of the kind normally treated in textbooks on informal logic. Suppose we were to try to model the argument in this case using the standard argumentation tools of an argument map and argumentation schemes. The resulting argument map would look something like the one shown in figure 1 . The statements in the textboxes are premises and conclusions while the circular nodes represent arguments. A textbox with a dashed rectangle as its perimeter represents an implicit premise that has been added in to tighten up the argument.

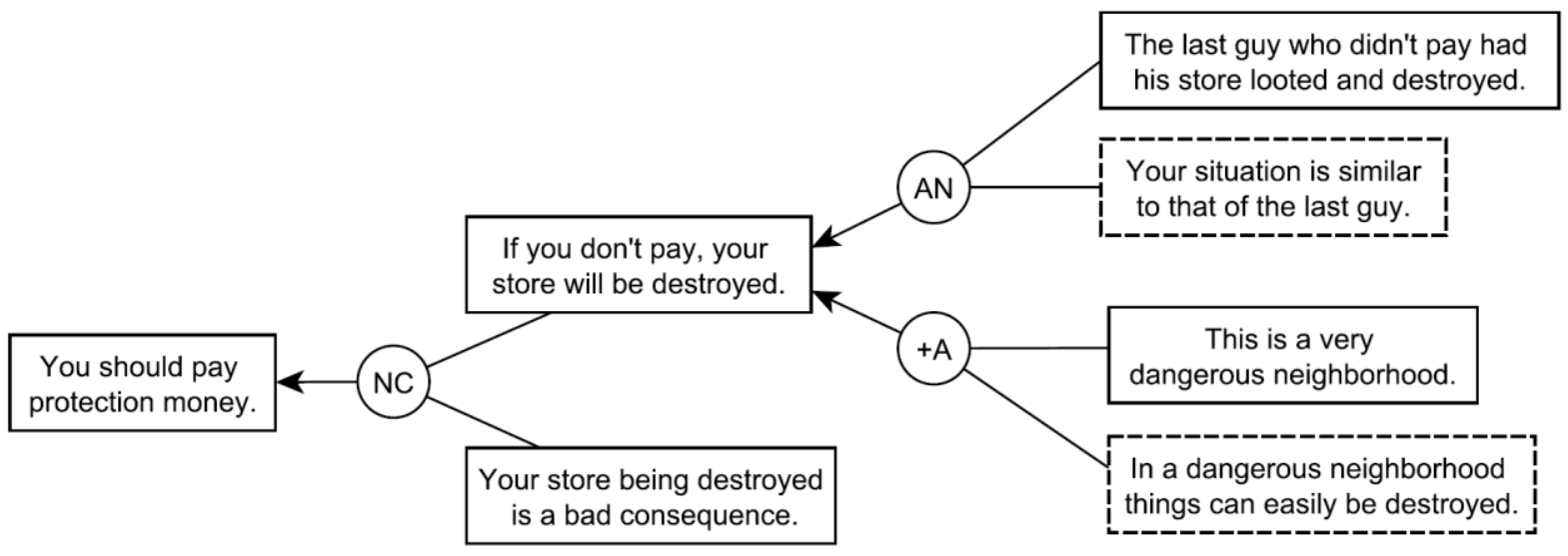

Figure 1: Argument in the Gangster Example

In the argument map shown in figure 1 the conclusion is shown as a directive to action. The gangster is telling the small business owner that it would be a prudent course of action for him to pay the protection money. He could be right about that. It could indeed be a prudent course of action for the small business owner to pay the protection money. So what is wrong with the argument, if it is supposed to be wrong?

To attempt to answer this question, let's try to situate the argument in a communicative context. The kind of argumentation involved is ostensibly that of a goal-directed deliberation in which one party is telling the other party how to do something, or giving him advice on how to do something by avoiding bad consequences. So conceived, how would we normally represent the structure of the argument in line with methods commonly in use in informal logic?

The method used to visually display the structure of the argument shown in figure 1 is to build an argument map showing the premises of the argument, the conclusions, the ultimate conclusion to be proved by the argument, and what kinds of arguments are used at each step in 
the sequence of argumentation. The two premises in the middle of figure 1 form a linked argument, and the type of argument is represented in the circular argument node labeled NC, representing the argumentation scheme for negative consequences.

Major Premise: If $A$ is brought about, then consequences $C$ will occur.

Minor Premise: Consequences $C$ are bad.

Conclusion: Therefore $A$ should not be brought about.

In the argument at the bottom right, two reasons are given to support the conclusion that there will be bad consequences if the store owner doesn't pay. This too is a linked argument, but the argument does not appear to fit any known argumentation scheme. Hence the notation $+\mathrm{A}$ is inserted in its node, indicating it is a pro argument of some yet unidentified type. The argument at the top right is also a linked argument, and as indicated in the node where the notation AN appears, this type of argument fits the argumentation scheme for argument from analogy. This is not the only way to analyze the structure of the argumentation in the case, but it does at any rate represent the typical way we would use argumentation tools to go about modeling the argument to show how the premises go together to support the conclusion.

However, notice that this way of analyzing the argument fails to bring out the most important aspects of it as a species of ad baculum argument. If you interpret the argument literally, as shown in figure 1, it is merely an argument from negative consequences supported by some backing evidence. However, this analysis is hopelessly incomplete and uninformative, from the point of view of seeing how the argument fits the scheme for the ad baculum argument, a form of argument that is essentially based on a threat or an appeal to force. We could add an implicit premise stating that the gangster is making a threat, but this doesn't seem to be appropriate or useful to explain what is really happening because making a threat is different from making a statement that can serve as a premise or conclusion of an argument. Making a threat would appear to be some kind of speech act that represents a way the argument is put forward, or that is somehow combined with the argument.

\section{Strategic Maneuvering}

To bring out what is really interesting about the argument and what is really important about it as an instance of the ad baculum fallacy, we have to bring in considerations of strategic maneuvering (van Eeemeren, 2010). The gangster has used a clever strategy. If the gangster were to directly threaten the owner of the small business by saying. "Pay protection money or your store will be looted and destroyed", he would be making an explicit threat of the kind that would likely be illegal, or at any rate would be inappropriate or irrelevant. Moreover, if he were to make such a direct threat, what he said would be so impolite and unpleasant to the small business owner that it might make the business owner himself want to somehow retaliate. So we can immediately see here some of the advantages of using an indirect threat.

The strategy of using an indirect threat gives the gangster what can be called an escape route for plausible deniability. If the small business owner were to ask the gangster whether he had just made a threat, the gangster can disingenuously reply, "I didn't make a threat: it was only a warning". There is very little in the way of explicit evidence that can be marshaled to prove that he did indeed make a threat. From the point of view of the study of fallacies, such a case is very interesting, because it is difficult to pin down the criticism that the gangster has committed a 
logical fallacy by making a threat of the kind associated with the ad baculum fallacy. It brings out a subtlety in the ad baculum fallacy, and moreover it is a subtlety that makes the fallacy difficult to analyze, and to pin on the party who has committed it.

Another interesting aspect of the case is that the type of argument used by the gangster appears to have the form of the argumentation scheme known as argument from negative consequences. This form of argument is commonly connected to examples of the ad baculum fallacy (Tindale, 2002, 109). As applied to the example, this type of argument runs as follows: if you fail to carry out action $A$, this failure to act will have negative consequences for you, therefore it is prudent for you to carry out action $A$. As noted in the paragraph above, on the surface this looks like, from the point of view of advice given by one party to another in a deliberation, it could be a reasonable argument. However, looked at from another point of view, it might seem that the gangster has put forward an argument, and therefore it might seem that he could reasonably be accused of committing a fallacy, since fallacies are generally considered to be bad arguments of some sort, and as noted above this argument generally seems to be somehow culpable or inappropriate. But is it really? Here we have to be very careful.

Although it may be that the gangster is putting forward some sort of argument, it is not a simple argument of the sort represented by the argumentation scheme for argument from negative consequences. It is much more than that. It is in fact clearly a threat, and the threat is being used to intimidate the small business owner, to put pressure on him to pay "protection money". So the interesting thing about this type of case is that it is more subtle than any more straightforward instance of the ad baculum argument in which a direct threat is made as the basis of the argument. Already we can see that another interesting thing about this example is that it calls for a speech act analysis, because making a threat can certainly be considered a type of speech act, but in this case the clever part of the strategy is that it is an indirect speech act. So let's investigate this way of seeing the argumentation.

\section{Indirect Speech Acts}

The canonical example of an indirect speech act is the question, 'Can you pass the salt?' If taken literally, it is simply a speech act of requesting information. So interpreted, it may be taken to ask the respondent whether she has the physical capability of passing the salt. But of course we all know that this is not the normal interpretation of this question in everyday discourse. Normally it is taken to be a polite request for the respondent to pass the salt, and it presumes that the respondent is in a position to reach the salt and has the capability to pass it along to the questioner. To move forward by analyzing the notion of an indirect speech act, it is necessary to bring in the theory of Gricean implicature.

The theory of Gricean implicature deals with cases in which the conventional meaning commonly associated with a sentence fails to correspond with a speaker's intended effect on her audience (Grice 1975; Levinson 1983, 97). The theory postulates that indirect speech acts can only be understood by interpreting them in light of underlying conversational postulates that Grice called maxims and we would nowadays in the argumentation literature call dialogue protocols (Macagno and Walton, 2013). Grice $(1975,71)$ offered the example of the professor who is asked by a student to write a letter of recommendation. The professor doesn't think very highly of the student's abilities, let's say, but nevertheless feels it is necessary for whatever reason to write such a letter on behalf of the student's job application for an academic position. So he writes something more or less trivial, for example he writes that this student has good 
manners and is punctual in coming classes. As we all know, a strong letter of application is necessary in order to help a person get a job, and so this very weak letter of recommendation will almost certainly fail to achieve this effect. Grice's theory of implicature is used to make the point by showing that the letter is unsatisfactory because it violates a normally accepted conversational postulate. In this instance, the writer of the letter is supposed to furnish information about the relevant skills of the applicant for an academic position, including her academic capabilities and so forth. The professor has failed to furnish the normally required sort of information for the letter to be helpful to support the student's job application. Therefore by implicature, and so by default, the letter actually written by the professor would be taken to sanction the reader of the letter drawing the conclusion that the student is not qualified, or at any rate not well enough qualified for the job. It is what is not said in the letter that is important and that triggers the implicature for the reader of the letter of reference to draw the conclusion that the professor is not recommending this student for the job.

Here we have an obvious parallel with the example of the ad baculum argument quoted above. It would appear that the professor's strategy in the letter of recommendation case is one of plausible deniability. If a student gets hold of the letter somehow and is outraged by it, the professor has the excuse that he didn't actually say anything negative about the student's abilities. He has not actually gone on record as saying this person is a poor or inadequate student, a claim which might be difficult to prove. Another motivation might be that the professor wishes to avoid a lawsuit if this happens.

\section{The Speech Acts of Giving a Warning and Making a Threat}

So here we have an example of an ad baculum argument that is interesting in many ways, and that challenges us to find an analysis of it using argumentation methods based on concepts drawn from speech act theory, and in particular the notion of an indirect speech act.

According to the analysis of the speech act of making a threat given in (Walton, 2000, 127), the speech acts of giving a warning and making a threat are closely connected. What is important on this analysis is not only the verbal formulae used to make the threat, but attention has to be paid to pragmatic features of the context of dialogue in which the speech act has been put forward as a locution. As noted above, the hearer needs to draw the conclusion that the arguer is making a threat by implicature from the conversational maxims appropriate for the context of dialogue. According to the definition of the speech act of making a threat given in (Walton 2000, 113) there are four speech act conditions that have to be met.

\begin{tabular}{|l|l|l|}
\hline Preparatory Condition 1 & $\begin{array}{l}\text { The hearer has to have reasons to believe that the speaker can } \\
\text { bring about the negative consequences in question. }\end{array}$ & C1 \\
\hline Preparatory Condition 2 & $\begin{array}{l}\text { It is presumed by both the speaker and hearer that the negative } \\
\text { consequences will not occur without the intervention of the } \\
\text { speaker. }\end{array}$ & C2 \\
\hline Sincerity Condition & $\begin{array}{l}\text { The negative consequences will not be in the hearer's interests } \\
\text { and the hearer would want to avoid them if possible. }\end{array}$ & C3 \\
\hline Essential Condition & $\begin{array}{l}\text { The speaker is making a commitment to make the bad } \\
\text { consequences occur unless the hearer carries out the action } \\
\text { recommended by the speaker. }\end{array}$ & C4 \\
\hline
\end{tabular}


Table 1: The Four Requirements Defining the Speech Act of Making a Threat

The essential difference between the speech act of giving a warning and the speech act of making a threat is the existence of $\mathrm{C} 4$. The essential condition is characteristic of the speech act of making a threat, and is characteristically absent when the speech act of giving a warning is made. Unless the essential condition $\mathrm{C} 4$ is present in a given case, the speech act needs to be classified as constituting a warning, and not as constituting a threat.

\section{Analysis of the Example}

In the gangster example, what has to be factored in is a consideration additional to the logical structure represented by the argument map in figure 1. A determination has to be made that what the gangster says is best interpreted as the making of a threat to the small business owner in light of the conversational maxims governing the argumentation in this case. The evidence comes in to make such a determination in several subtle ways. One is that the man informing the business owner about the negative consequences is known to be a gangster, meaning that he has the capability for carrying out the negative consequences, and has the reputation of someone who is known to carry out illegal acts of this sort. There is some other evidence as well. The gangster informs the small business owner that this is a very dangerous neighborhood. From a Gricean point of view, this is useless information for the gangster to give the small business owner because both of them presumably know whether this neighborhood really is dangerous or not. So the communicative function of the gangster's asserting this proposition to the business storeowner is not one of the one party informing the other by passing along to the other some piece of information that the other does not know. Apparently the reason why the gangster would presumably add the assertion that this is a very dangerous neighborhood is that he wants to distance himself from being interpreted as having made a direct threat. He is suggesting that because it is a dangerous neighborhood the business owner store could potentially be looted and destroyed by anybody, not specifically by himself.

But there is also an ambiguity. As shown in figure 1 the statement that this is a very dangerous neighborhood can also function as a premise in an argument along with the implicit premise that in a dangerous neighborhood things can easily be destroyed. These statements then can be seen to make up an additional reason why the owner should pay protection money, because if he doesn't pay his store will be destroyed.

So when the gangster adds the statement that this is a very dangerous neighborhood, there is an aura of irony to this statement that we can all recognize. We know that the gangster is making an indirect threat to destroy the store if the storeowner doesn't comply to pay protection money. But the gangster is distancing himself from the possibility of future repercussions of having made an explicit threat by two strategic means. One is the use of the indirect speech act which on the surface has the appearance of a warning, but under the surface really is a threat. The other is the strategic device of distancing himself even further from the allegation of having made a threat by saying in an ironic tone of voice, "This is a very dangerous neighborhood".

\section{Conclusion}


The analysis of the gangster example in section 5 has shown that there is plenty of evidence that what the gangster said can be taken to be a threat, and not merely a simple argument from negative consequences. What the gangster said is ambiguous. It can be taken either way, and he takes advantage of this ambiguity to leave an escape route for plausible deniability, should he be accused of having made a threat. The keys to unraveling the ambiguity in the case and critically analyzing it are: (1) the notion of an indirect speech act and (2) the definition of the speech act of making a threat. As indicated in the previous section, there is sufficient evidence to adequately fit the text of what the gangster says into the category of making a threat. It fits all four requirements of the speech act of making a threat. It fits the first preparatory condition, provided that the small business owner recognizes that the person is talking to is a known gangster who is in a position to bring about the destruction of his shop. It fits the second preparatory condition, provided it can be assumed that the destruction of the shop would not occur without the intervention of the gangster. It fits the sincerity condition, assuming that the destruction of the shop would not be in the small business owner's interests, and that he would want to avoid these consequences if possible. It fits the essential condition, assuming that the gangster is making a commitment to see to it that the shop is destroyed unless the small business owner pays him the protection money.

The presence of all four conditions can arguably be held to be there in the case, based on the evidence that can be extrapolated from the case using the indirect speech act of making a threat. The evidential problem posed by the case is we that have to evaluate the ad baculum argument from the textual evidence actually given, including both what the gangster actually said and what can be derived from what he said using the contextual information in the case. This task was carried out by combining three tools: (1) implicature, (2) the speech act of making a threat, and (3) indirect speech acts.

References

Budzynska, K. and Witek, M. (21014). Non-Inferential Aspects of Ad Hominem and Ad Baculum, Argumentation, to appear.

Grice, H. P. (1975). Logic and Conversation, Syntax and Semantics, vol. 3, ed. P. Cole and J. L. Morgan. New York: Academic Press, 1975, 43-58.

Levinson, S. (1983). Pragmatics, Cambridge: Cambridge University Press.

F. Macagno and D. Walton (2013). Implicatures as Forms of Argument, Perspectives on Pragmatics and Philosophy, ed. A. Capone et al. Berlin: Springer, 203-224.

Reed, C. (2011). Implicit Speech Acts Are Ubiquitous. Why? They Join the Dots, Zenker, F. (ed.). Argument Cultures: Proceedings of the 8th International Conference of the Ontario Society for the Study of Argumentation (OSSA), May 18-21, 2011. Windsor, ON (CD ROM), 115.

Tindale, C. W. (2007). Fallacies and Argument Appraisal. Cambridge: Cambridge University Press. 
Van Eemeren, F. H. (2010). Strategic Maneuvering in Argumentative Discourse. Amsterdam: Benjamins.

Walton, D. (2000). Scare Tactics. Dordrecht: Springer. 